\title{
Collisions between Institutional and Populist Risk Imaginaries: the "dark side" of negative asymmetric thinking
}

\author{
Ryan Hagen ${ }^{1}$
}

\begin{abstract}
Expert knowledge informs the construction of public problems from gun violence to disease epidemics to climate change, and institutional actors draw on this knowledge to implement public policy to mitigate or repair the related harms. The expanding role of experts and institutions in managing risks has come at a time of declining public trust in institutions and a legitimacy crisis around expert knowledge. What happens when these tendencies collide? Previous scholarship has examined how disaster arises through failures of foresight, and how culturalcognitive biases can prevent actors from seeing disasters coming. Less is known about the mobilization of resistance against risk management policies. This theoretical essay examines a particular category of that resistance: conspiracist discourse that frames risk as emanating primarily from perceived secret agendas of institutions and experts that explicitly claim to be acting in the public interest. This essay argues that conspiracy thinking can be best understood as rooted in a "populist risk imaginary," which is rooted in negative asymmetry, a culturalcognitive bias that foregrounds the possibility of worst-case outcomes. Conspiracy discourse can be understood as the "dark side" of negative asymmetry, which is otherwise used by service-oriented professionals to sharpen their foresight in preempting future dangers.
\end{abstract}

KEYWORDS: risk; politics; culture and cognition; the future.

\footnotetext{
${ }^{1}$ Department of Sociology, Columbia University, $606 \mathrm{~W} 122^{\text {nd }}$ Street, New York, New York 10027; e-mail: ryan.a.hagen@columbia.edu
} 
"The thought keeps suggesting itself (the 'insane' thought par excellence) that, perhaps, the bright reality of everyday life is but an illusion, to be swallowed up at any moment by the howling nightmares of the other, the night-side of reality." - Berger and Luckmann, The Social Construction of Reality.

\section{INTRODUCTION}

The term "resistance" in U.S. popular political discourse since the 2016 election has been associated primarily with left-wing protest against President Donald Trump and his agenda. Among the most striking early examples of this were the Women's March that followed Trump's inauguration in January 2017, and the mass mobilizations at U.S. airports later that month to protest the new administration's harsh restrictions on refugees and travelers from seven majority-Muslim countries. The work in this special issue has mostly explored progressive resistance amid the broader reactionary political climate of recent years.

In this essay I direct our attention to a different mode of resistance, in the form of populist dissent against expert knowledge and institutions. Rather than contesting public policy - for example whether or not abortion should be legal, whether the U.S. should be involved in foreign wars, or the appropriate level of taxation - this mode of resistance contests the fundamental legitimacy of the expert knowledge claims that underpin much of common political discourse itself. What is specifically populist about this mode of resistance is that its adherents portray experts as not simply wrong or out of touch, but as morally corrupt, or even predatory, as defined against the virtuous common sense of 
everyday people (Mudde 2004; Bonikowski and Gidron 2016; Brubaker 2017). Prominent within this resistance is conspiracy thinking: the notion that an elite cabal is secretly working to undermine the will and wellbeing of the people. This conspiracy thinking primarily seeks to delegitimize institutions and experts, the political philosophers Russell Muirhead and Nancy Rosenblum argue, denying them their "standing in the political world to argue, explain, persuade, and decide" (Muirhead and Rosenblum 2019).

The belief in conspiracies as a driving force in history is broadly present in the U.S. population. A national survey in 2012 found that 30 percent of Americans agreed explicitly that "big events like wars, the current recession, and the outcomes of elections are controlled by small groups of people who are working in secret against the rest of us," while another 38 percent neither agreed nor disagreed (Uscinski and Parent 2014). A 2013 survey found that 37 percent of Americans believed the Food and Drug Administration was deliberately withholding natural cures for cancer under pressure from profit-seeking pharmaceutical companies; 20 percent believed physicians and government officials advocated vaccination even though they knew vaccines caused autism and other disorders; 12 percent believed the development of genetically modified crops was part of a secret plot by the Rockefeller and Ford foundations to shrink the global population. These beliefs shaped behavior. Reported belief in more than one conspiracy theory was associated with resistance to routine medical interventions including flu vaccination, annual physical examinations and dental visits (Oliver and Wood 2014). More generally, belief in 
conspiracy theories has been shown to decrease civic engagement and depress other prosocial behavior (Jolley and Douglas 2014; van der Linden 2015; Jolley et al. 2019).

How can we make sense of this phenomenon sociologically? The phrase "conspiracy theorist" is commonly deployed as a tool of dismissal and exclusion (Husting and Orr 2007), and much of the previous literature on this topic either focuses on psychological factors or the political determinants and consequences of conspiracism (DiGrazia 2017). Instead, in this theoretical essay I take conspiracy theorizing seriously as a form of cultural cognition. For analytical leverage, and to move away from the pejorative term "conspiracy theorizing," I develop the notion of a "populist risk imaginary" that positions elites and institutions - corrupt, predatory, and omnipotent - as the motive force behind risk and disaster in the modern world. I use the term populism in line with recent work framing populism as a style of mobilization and rhetoric rather than a specific ideology or political program (Brubaker 2017). Populism is a style of rhetoric, discourse, and thought that "mobilizes ordinarily marginalized social sectors into publicly visible and contentious political action, while articulating an anti-elite, nationalistic rhetoric that valorizes ordinary people" (Jansen 2011: 82). The populist risk imaginary is a mode of thought that defines itself against what can be called the institutional risk imaginary, which conceives of risk and disaster as public problems that can be detected, measured, and managed through expert systems, instruments, and organized social control.

The populist risk imaginary arises from what Karen Cerulo has called "negative asymmetric thinking," described as an "emancipating structure" that allows actors to 
deviate from preconceptions that would blind them to the possibility of negative outcomes (Cerulo 2006). Negative-asymmetric thinkers foreground the worst-case scenarios that without preemptive action might confront them in the future. Similarly, the populist risk imaginary promises emancipation through foregrounding the worst possible outcomes of and motives for institutional risk management.

Where the institutional risk imaginary perceives a rise in mass shootings and invites debate over the appropriate scope of Second Amendment rights to gun ownership, the populist risk imaginary frames mass shooting events themselves as hoaxes perpetrated by shadowy figures in the service of authoritarian ends. Similarly, debate over the correct policy responses to the threat of terrorism becomes in the populist risk imaginary a debate over whether or not events like the $9 / 11$ attacks were "false flag operations" carried out or enabled by government elites specifically in order to justify intrusive security and surveillance measures. Scientific knowledge claims about global climate change are dismissed as not simply mistaken, but as maliciously fabricated by elite scientists conspiring in pursuit of a liberal agenda (Gauchat 2015). In the realm of public health, some strands of resistance against vaccination have in recent years taken on a similar populist aspect - a belief that medical experts, scientists and regulators are conspiring with the pharmaceutical industry to push vaccines they know to be unsafe and ineffective in order to enrich themselves (Reich 2016).

That people believe duplicitous elites are conspiring to cause harm in the world is not itself new. In the 1960s Richard Hofstadter demonstrated the persistence of what he 
called the "paranoid style" in American political culture, tracing a connection from 17th Century fears about global Freemasonry through to elaborate stories of communist infiltration in the middle of the 20th Century (Hofstadter 1996). At least two recent developments however are worth considering. The first is the consistent and successful use of rhetoric appealing to the populist risk imaginary by a major party presidential nominee, who continues to deploy it while in office. This comes against the background of the second development: the expanding role of institutional risk management in public life, which is to say the growth of the institutional risk imaginary.

In the years leading up to his campaign for the presidency, Donald Trump routinely promoted or endorsed conspiracy theories: that President Barack Obama was secretly born outside the United States; that climate change was a hoax perpetrated by the Chinese government; that vaccination caused autism. A central theme in his campaign was that hidden global forces were conspiring to undermine American interests: that the Mexican government was intentionally sending criminals across the border into the U.S. for example, that his opponent Hillary Clinton was working with — in his words — "a global financial elite to plot the destruction of U.S. sovereignty," (Hochschild 2016) or that unspecified enemies would carry out voter fraud to deprive him of victory in the election.

This departure from normally accepted political rhetoric was key to Trump's political appeal (Wagner-Pacifici and Tavory 2017). Embracing conspiracy theories that were outside the bounds of respectable politics was part and parcel with the Trump 
campaign's resonance with disaffected voters as "a vacation from a politics of bureaucratic rules, forms, and policies that promised melioration but were often experienced as obstacles" (Wagner-Pacifici and Tavory 2017: 318). Indeed, on the eve of the 2016 election, Arlie Hochschild wrote that many of the Louisiana conservatives she came to the know in the process of researching her book Strangers in Their Own Land had been drawn to Trump exactly because of this style of rhetoric. They supported him "because of his penchant for conspiracies, not in spite of it" (Hochschild 2016).

The success of Trump's populist attacks came amid a decades-long erosion of public trust in institutions (Twenge et al. 2014) and a sense among voters that public issues are unfolding in a space "beyond their reach" (Perrin and Vaisey 2008: 782). At the same time, institutions and experts have assumed an ever-expanding role in detailing the risks we face and intervening in everyday life to manage them. Public health experts monitor disease outbreaks and warn that we are unprepared for the "next pandemic" (Lakoff 2017); counterterrorism and security experts warn about the need for preparedness against the "next terrorist attack" (Aradau and van Munster 2012; Molotch 2012; Stampnitzky 2013); meteorologists issue increasingly long-term and detailed forecasts of severe weather (Fine 2007; Daipha 2015) while climatologists describe the dangers of a climate destabilized by human carbon emissions (Dunlap and Brulle 2015). These are some facets of the reorganization of public life around risk consciousness described by Ulrich Beck and Anthony Giddens as the Risk Society (Giddens 1990; Giddens 1991; Beck 1992; Beck 2009). Under the Risk Society, institutions have oriented their risk management strategies 
around anticipation and preemption, rather than insurance and recovery (Collier 2008; Anderson 2010). Faced with risks that are uninsurable, governments and corporations increasingly look to mitigate future dangers through anticipatory governance, in an "effort to transform encounters with risk into routine, formalizable processes - literally to organize uncertainty" (Power 2005: 147).

It should perhaps be no surprise that these two attitudes towards risk - the elite belief that future disasters can in a meaningful way be controlled and the populist belief that elites control disastrous events - sometimes collide head on. That is to say, in a cultural milieu in which risk and disaster are perceived as increasing alongside the broadening scope of institutional risk management, some people draw the conclusion that these institutions are intentionally creating danger, rather than preventing or ameliorating it.

For example, when in 2017 the Federal Emergency Management Agency announced it would conduct an exercise simulating the government's response to a small-scale nuclear attack on the New York City area, the popular conspiracy site Info Wars, whose publisher Alex Jones has been praised by Trump, posted an item speculating that the exercise could be cover for a real nuclear attack on the country, perpetrated by the government as an excuse to implement martial law ${ }^{2}$. The story extended a long-running and highly

\footnotetext{
${ }^{2}$ InfoWars. "Operation Gotham Shield: U.S. Gov't To 'Simulate Nuke Blast Over Manhattan' As Actual War Nears." https://www.infowars.com/operation-gotham-shield-u-s-govt-to-simulate-nuke-blast-overmanhattan-as-actual-war-nears/
} 
elaborated set of narratives that have been broadly held among right-wing fringe groups since the early 1980s. In these narratives, FEMA's disaster preparedness activities are reimagined as methodical preparations for an authoritarian takeover of the country from within (Barkun 2006; Keller 2010).

The case of the Holy Fire, a wildfire that burned more than 20,000 acres in Southern California in August and September of 2018, provides a more acute example. In the period leading up to the fire, California had faced two consecutive years of recordsetting wildfire damage, provoking a sustained response from the state, and claims from the scientific community that global warming was a contributing factor. Meanwhile, stories circulating online claimed to unmask a conspiracy by the government to deliberately set the wildfires as a pretext for enacting land use reforms under the authoritarian influence of the United Nations. This theory built on a broader family of narratives centered around the idea that the U.N.'s Agenda 21 sustainable development program is in fact a sinister plot to undermine U.S. sovereignty through local and regional land use planning measures. This idea has been adopted by conservative activists, who have mobilized around it to derail local sustainable development projects across the country (Norton 2014; Trapenberg Frick et al. 2015). The idea that the state was intentionally setting wildfires was explicitly referenced on social media by the California man who, authorities allege, set the Holy Fire himself. The alleged arsonist, shortly before the fire started, contacted the chief of the local volunteer fire department, sending him a 
text message reading "it's all going to burn like you planned" (Cosgrove et al. 2018; Dalrymple II 2018).

These two examples are indicative of a broader worldview in which institutions that claim to be acting in the public interest to manage risk are instead understood as the primary sources of risk in society. In the remainder of this essay I will argue that this populist risk imaginary emerges as a form of negative-asymmetric thinking that sets itself in opposition to the professional fields of institutional risk management. Just as bureaucracy has both a "bright side" that brings benefits and a "dark side" that leads to unintended harms (Vaughan 1999), negative asymmetric thinking has a dark side, in this case unified around the idea that the greatest dangers we face come from the institutions that claim to be keeping us safe. By understanding conspiracist belief as populist risk cognition emerging from negative asymmetric thinking, we can better see the holders of these beliefs as knowledgeable actors in the social construction of reality rather than as political dupes who are simple victims of misinformation. Prior research has shown how fringe ideas move towards mainstream acceptance through appeals to fear and anger (Bail 2012; Bail 2014). But we have more to learn about how that fear is structured, and why these appeals resonate with some people more than others. The concept of the populist risk imaginary suggests a way forward in that regard. 


\section{ASYMMETRIES IN FUTURE PROJECTION}

While it is a sociological commonplace that action in the present is shaped by circumstances "directly encountered, given and transmitted from the past" (Marx 2008: 15), recent scholarship has turned to investigate how these encounters, these gifts, these transmissions might also arrive from the future, inscribed in the present by coordinated predictions about the outcome of purposive action. How are people's actions influenced by their projections of the future (Mische 2014)? How are everyday interactions between people shaped by the necessary work of coordinating expectations for what will happen in the near-, intermediate-, and long-term (Tavory and Eliasoph 2013)? A particular area of interest is how and why individuals and organizations fail to productively anticipate significantly disruptive events. Time and again, following natural disasters, jetliner crashes, or economic crises, how can it be said that the relevant actors "never saw it coming" (Cerulo 2006)?

One hypothesis is that a cultural bias towards positive outcomes systematically blinds actors to detailed projections of undesirable futures, precluding thinking that might allow these outcomes to be avoided. Applied to social life broadly, Karen Cerulo's concept of "positive asymmetry" suggests that most actors operate under a cultural tendency to project the best possible future results of present action, while clouding negative or worstcase outcomes. Within organizations, planners faced with the possibility of unmanageable catastrophe may offer up "fantasy documents," detailed plans that narrate a rational, effective response to future calamity, but which are in fact "no more than vague hopes for 
remote futures [having] virtually no known connection with human capacity or will" (Clarke 1999: 16). Such plans may be strategically useful for defusing opposition to certain near-term actions on the grounds of their uncertain potential produce negative outcomes in the future. Over the long term however fantasy documents increase the likelihood of calamity by foreclosing the possibility of frank and detailed thinking about expectations of danger and the limits of knowledge and control. A recent application of the concept to the financial crisis of 2008 showed how positive asymmetric thinking caused Federal regulators to systematically underestimate the possibility that the crisis building in financial markets might spill over into the broader economy with catastrophic consequences (Fligstein et al. 2017).

Certain professional knowledge systems, Cerulo argues, free actors from the limitations of positive asymmetry by forcing a foregrounding of negative outcomes and worst-case scenarios. Medical practitioners and computer systems technicians, for example, focus on the detailed identification of dysfunctions and failures that lead to negative outcomes. These professionals produce prognoses of undesirable futures based on the ideal-typical worst outcomes and "think backward" to the symptoms that indicate these trajectories (Cerulo 2006:169). That is to say a doctor in a physical exam confronted with a patient complaining of chest pains will not ask if the patient's heart has been beating smoothly, or inquire about other signs of good health, but will rather focus on detecting specific signs of an impending heart attack. To this list of professional knowledge systems we might add meteorologists, who work with detailed models of atmospheric 
events for the purposes of predicting and warning against a set of ideal-typical dangers (Fine 2007; Daipha 2015). We might also consider disaster risk managers who, working in public health agencies, the Department of Homeland Security, or emergency management agencies at the local, state, and federal level, are charged with imagining worst-case scenarios in detail to prevent them or to mitigate their effects (Fosher 2009).

Cerulo posits four traits that, when present in combination in a professional field, serve as emancipating structures allowing for the emergence of negative asymmetric thinking. These are:

1) Service orientation: a dedication to improving the lot of others; in Weberian terms, a basic professional grounding in substantive rationality (value rationality) rather than formal rationality (amoral calculation).

2) A formal knowledge base: practitioners operate from a "set of explicit beliefs about the way in which elements of the world work [forming] a script for action that is highly articulated and self-consciously invoked ... [which is] understood as a product of continual discovery" (Cerulo 2006:189) as opposed to basing action on "traditional" or "common sense" knowledge.

3) Porous boundaries: the field encourages the free flow of information, people, and resources into and out of the community. This is often coupled with the first trait - information is freely shared with the public as a service aimed at improving health, safety, or quality of life. 
4) Professional autonomy: a relative freedom to work and make decisions with little restriction from external authority.

These traits combine in organizations or communities that feature a web-like hierarchical structure that allows for low-friction multi-directional communication between an organizational core and the periphery, as opposed to a more vertical "M-form" hierarchy dominated by a central command peak that dominates the chain of command and is subject to control by external authorities. In combination, these traits may "loosen the hold of routine cultural practices, freeing groups and communities to pursue unanticipated problems and creative solutions" (Cerulo 2006:194).

The bright side of negative asymmetry is the potential for actors to productively envision negative outcomes so as to avoid them. Scholars of High Reliability Organizations showed as much in their studies of systems like air traffic control and nuclear-powered warships in which a preoccupation with failure, deference to local expertise, and constant multi-directional communication are cultural practices seen to reduce the risk of failure in complex, high-risk operations (Weick 1987; Roberts 1990; Bierly III 1995; Vogus et al. 2014).

The dark side, on a psychological level, is intractable pessimism, a crippling tendency to focus on negative outcomes to the exclusion of the achievement of positive goals. On a social level, it may generate apocalyptic cults, or violent extremists. For instance, the anthropologist Mark Juergensmeyer, in his comparative study of religious 
violence, argued that an animating feature of the logic of religious terror was the construction of social reality as a "cosmic war" between believers and non-believers, a state in which the forces of good are under siege by the forces of evil (Juergensmeyer 2003).

A middle ground between individual depressives and apocalyptic cults may be the everyday conspiracists who embrace the populist risk imaginary. An Alex Jones progenitor, Mae Brussell, who rose to prominence in the 1970s as a radio host who spun elaborate theories to account for the assassination of President John F. Kennedy, inadvertently made the case for negative asymmetric thinking in explaining her career to a journalist: "[After the JFK assassination] I wanted to find out if there had been a coup, if the United States was going fascist. Would I be like Anne Frank's father, who told his family that things were OK and that people were basically good - while they were living their last days? With a family of five children, my husband and myself, I had an obligation to understand the world outside my home" (Brussell 2014). The populist risk imaginary promises to emancipate its adherents from the naively optimistic belief that disasters are accidents of history, when they are - according to this construction of reality - always the deliberate consequences of elite power.

\section{NEGATIVE-ASYMMETRIC TRAITS OF THE POPULIST RISK IMAGINARY}

\section{Service Orientation}

Mae Brussell's insistence that she set out to uncover "the truth" about the Kennedy assassination out of an obligation to protect her family hints at the presence of a service 
orientation in the populist risk imaginary. This is consistent with the claims populists more generally make that they are protecting "the people," however that group is defined, from outside threats (Brubaker 2017). Here, the act of protection consists mainly in raising awareness - warning others of the covert plots around them. Hofstadter described the selfconception of the ideal-typical conspiracy theorist as "a member of the avant-garde who is capable of perceiving the conspiracy before it is fully obvious to an as yet unaroused public ... a militant leader" (Hofstadter 1996: 30-31). More recently the political scientists Joseph Uscinski and Joseph Parent argued that conspiracy discourse, deployed by members of groups who feel themselves disadvantaged or under threat, "has a strategic logic. Sharing conspiracy theories provides a way for groups falling in the pecking order to revamp and recoup from losses, close ranks, staunch losses, overcome collective action problems, and sensitize minds to vulnerabilities" (Uscinski and Parent 2014: 132).

This notion of liberation through the sharing of secret knowledge is captured in the term "red pilling," used commonly in online communities on boards like 4chan and Reddit as a metaphor for consciousness raising among the uninitiated (Marwick and Lewis 2017). The term originates from the 1999 science fiction film The Matrix, in which the protagonist, Neo, discovers that the reality he has been experiencing is in fact a computer simulation meant to pacify an enslaved human race. Neo's discovery begins with a gift from a stranger. He is given the choice of swallowing either a red pill, which will reveal the hidden forces that imprison him, or a blue one, which will allow him to continue living 
in his uneventful, deceived reality. What the term "red pilling" connotes here is a sense of duty to pass on the gift of knowledge - to recruit others into their skeptical worldview.

In its service orientation, the populist risk imaginary is doubly empowering. First, as a way of providing individuals who feel powerless in the face of the sprawling, impersonal institutions and power structures of modernity a coherent narrative: they are protagonists who have unmasked a plot against themselves and their community. Secondly, it empowers them as agents of liberation, awakening others to their newly discovered reality. This proselytizing logic ensures that narratives rooted in the populist risk imaginary will be circulated.

\section{Formal Knowledge Base}

The revelatory nature of conspiracy narratives rooted in the populist risk imaginary points to a second characteristic also common to sites of negative asymmetry: the prevalence of formal knowledge. Formal knowledge within the populist risk imaginary comes as a framework of evidence, terms, and connections between events and actors that collectively purport to undermine the "official story" of some historical event or traditional understanding of power and threat in society. It is self-consciously evoked as nontraditional, as overturning common-sense explanations of how the world works. Terms like "The New World Order," "The Illuminati," and "false flag" carry special significance within these communities, used as components in the weaving together of conspiracy narratives (Barkun 2006). 
As Hofstadter argued, an identifying trait of conspiracy theory is "the quality of pedantry ... the elaborate concern with demonstration it almost invariably shows" (Hofstadter 1996: 36). Formal knowledge supporting the populist risk imaginary is highly flexible, insofar as it is able to incorporate new information in pursuit of elaborating and protecting its core assumptions. Indeed failed predictions and contradicting evidence are often incorporated into the narratives themselves as proof of a cover-up. This accounts for the often baroque nature of conspiracy narratives, as alternate explanations, facts, and modifications accumulate in defense of the theoretical claims (Clarke 2002).

This obsession with the accumulation of evidence is especially apparent on online discussion boards where conspiracy theory groups congregate. Following the bulk release of emails hacked from Clinton campaign chairman John Podesta in 2016, users of the online forums Reddit and 4chan began to collaboratively sift through the archive in search of incriminating evidence. Seizing on what they interpreted as coded language within the emails, which was later combined with a heterogeneous mixture of verifiable and fantastical information available on the internet, they gradually assembled a theory linking Podesta, Clinton, and the Democratic Party establishment to what they imagined to be an occult child sex trafficking operation run out of the basement of a Washington, D.C. pizza restaurant. Members of the boards understood themselves as progressively uncovering a world-shattering scandal concealed by a corrupt elite. Referencing the Watergate scandal of the Nixon era, they called their project "Pizzagate" (Aisch et al. 2016). The theory was taken seriously enough by members of the online community that 
in December of 2016 one of them drove six hours from his home in North Carolina to the restaurant to investigate the claims in person. He came armed with a rifle, and opened fire in the restaurant before being arrested by police.

\section{Porous Boundaries}

The service orientation that animates the populist risk imaginary - the imperative to protect others by circulating claims of covert institutional predation - is closely linked to the porous boundaries of communities embracing this style of thought. Knowledge is exported prolifically, through professional media channels like Info Wars and documentary films like "Vaxxed: From Coverup to Catastrophe," directed by the disgraced gastroenterologist Andrew Wakefield, which argues that the Centers for Disease Control corruptly hid evidence of a link between autism and the MMR vaccine. Official public conferences are organized and held for networking and consciousness raising - among the most high-profile of these was the first annual "Flat Earth Conference," held in Raleigh, North Carolina in 2017, a two-day event dedicated to exposing a purported conspiracy among scientists to deceive people about the shape of the planet. While the conference focused on the supposed sinister lie of heliocentrism, the boundaries between different narratives within the populist risk imaginary are easily crossed, and different strands of conspiracy narratives are commonly woven together. One speaker at the event described his intellectual journey to belief in the Flat Earth story through the consumption of online video: 
We went from one thing to another to another-Sandy Hook, 9/11, false flags ... We got into the Bilderberg, Rothschilds, Illuminati. All these general things that one ends up looking into when you go on here, because you look at one video and then another suggestion pops up along the same lines. ... Each thing started to make that much more sense I was already primed to receive the whole flat-Earth idea, because we had already come to the conclusion that we were being deceived about so many other things. So of course they would lie to us about this. (Burdick 2018)

This suggests a broader disposition to attribute the causation of everyday events to the hidden forces of corrupt elites. This has been a finding of psychological research into conspiracy belief. As Viren Swami and colleagues reported, in a survey study of British and Austrian public opinion: "the strongest predictor of whether or not an individual will ultimately accept a conspiracy theory is the presence of earlier conspiracist ideation" (Swami et al. 2011: 459).

The passage above also highlights the key role of social media platforms in recruiting new adherents to the populist risk imaginary and in circulating information to new audiences. These platforms, built around unrestricted interconnection and community building, have long had a reputation for democratizing discourse, both of which resonate with populism's suspicion of mediated communication. They encourage the kind of disciplinary boundary crossing characteristic of negative asymmetry. The researcher Rebecca Lewis documented one such online community: influential producers of fringe right-wing content on YouTube (Lewis 2018). The community is linked through "guest appearances," conversations, and multi-party debates between video commentators on one 
another's channels. The resulting network constitutes an alternative source of information, putting news and political commentary alongside conspiracy theorizing, across "a range of political positions from mainstream versions of libertarianism and conservativism to overt white nationalism" (Lewis 2018: 10). The relative ideological diversity of this community, paired with the recommendation algorithm of the platform, makes it easy for new viewers to be exposed to increasingly radical content.

On social media, information with an element of novelty spreads most quickly and widely, which means that unverified rumors, along with misinformation and disinformation, are more broadly consumed than corrections or incremental updates to existing stories (Vosoughi et al. 2018). The incentive to post novel information can be an incentive to cognitive deviance generally, and negative asymmetry in particular: stories that provoke anger or outrage, for example at elite corruption, are more likely to be engaged with and spread.

\section{Autonomy}

The final trait of negative asymmetric thinking is generally associated with professional fields: individual autonomy. Professionals in fields where negative asymmetry thrives have high degrees of individual freedom of choice over how they carry out their work. On a larger scale, organizational structures that provide smaller units and divisions greater autonomy, rather than tight hierarchical integration, tend to facilitate negativeasymmetric thinking. Communities embracing the populist risk imaginary do show high 
levels of autonomy, in part because no professional field, and so no recognized constraining authority, is present. It would be difficult to argue that conspiracy theorizing is a profession. Media figures, like Alex Jones, Glenn Beck, and Mae Brussel before them, who formulate and propagate conspiracy narratives are perhaps best categorized as media professionals who operate within a specific style. Politicians, like Donald Trump, who draw on and appeal to the populist risk imaginary in their rhetoric, are likewise more usefully considered as politicians rather than professional conspiracists.

But populism highly values individual autonomy, distrusting institutions and mediating organizations of all kinds, and experimenting with horizontal and broadly participatory forms of involvement and cooperation (Brubaker 2017: 366). Furthermore, it could be that people with an affinity for the populist risk imaginary are characterized by too much autonomy: the marginalized, people who experience alienation and anomie.

Cerulo notes that negative asymmetry emerges from a general structure composed of traits in combination, rather than a set of characteristics bound up in professional identity, leaving open the possibility that beyond professional fields "any group or community structured in this way can leave positive asymmetry behind." (Cerulo 2006: 193). 


\section{DISCUSSION AND CONCLUSION}

The abuse of power by elite institutions, especially when that abuse is directed at vulnerable populations they are supposed to serve and protect, is a worst-case scenario. Positivity bias might blind actors to patterns of abuse and misconduct by institutions or individuals in positions of power. Negative asymmetric thinking, emerging from the combination of a service orientation, formal knowledge base, porous boundaries, and autonomy, can set groups free of perceptual biases that blind them to the possibility of certain negative outcomes. At its best, this style of cultural-cognitive deviance uncovers abuse, and exposes wrongdoing. After all, conspiracies and cover-ups do happen. And indeed the argument of this essay is not to cast all skepticism of scientific knowledge as fringe and cognitively suspect. Contests over the legitimacy of scientific and medical risk knowledge are routine features of a risk society (Wynne 1989; Cable et al. 2008). What I mean to draw attention to is a mode of resistance against institutional risk management projects that has a uniquely anti-elite character, seeking to mobilize "ordinary people" against the far-reaching covert plots of corrupt elites to harm them.

Negative asymmetry has a dark side, introducing corrosive skepticism against wellmeaning institutions and exacerbating social distrust and the crisis in expertise. In a political moment in which the President of the United States routine invokes conspiracy theories to explain the actions of his own government, his political opponents, and the news media, negative asymmetry becomes a source of divisiveness and social instability.

Like the "fantasy documents" that paint unrealistically rosy but strategically useful future 
projections of organizational performance under disaster conditions, conspiracy narratives conceived within the populist risk imaginary have strategic usefulness in mainstream politics. Dark fantasies about the United Nations' Agenda 21 were adopted and spread by Tea Party activists and used as the basis for anti-sustainability legislation introduced in nearly half of U.S. state legislatures (Trapenberg Frick et al. 2015). Republican politicians courted conspiracy theories about the Affordable Care Act, the legitimacy of Barack Obama's birth certificate, and the attacks on U.S. facilities in Benghazi, Libya, as a means to mobilize their supporters and muddy the public debate around President Obama's agenda (Warner and Neville-Shepard 2014; Miller et al. 2016).

Closer to the present, when calls for gun control regulation flooded the public sphere following the mass shooting at Marjory Stoneman Douglas High School in Florida in February 2018, narratives circulated online speculated that the shooting had been staged as a pretext for authoritarian measures to strip gun owners of their firearms. For a time, following the shooting, the most recommended video on YouTube was a clip claiming that student survivors of the event were "crisis actors" paid to fake the event (Herrman 2018). The video built on narratives previously circulated by Alex Jones that the 2012 school shooting in Newtown, Connecticut, was also a media spectacle staged by the government to build support for disarming its citizens (Williamson 2018).

This essay has tried to take conspiracy thinking seriously as a structured form of cultural cognition, as a manifestation of a populist risk imaginary arrayed against institutional risk management. Framing the phenomenon this way provides an analytical 
lever into understanding the sources and meaning of a significant variety of political opinion and mobilization in the early 21st Century.

There is a dearth of empirical research on people and groups that embrace conspiracy theories. Much of what does exist is in the political science and psychology literature. Future research within sociology might examine the perception and use of conspiracy theories by political actors (Nefes 2013), or how actors push fringe narratives into the mainstream in support of their agenda (Bail 2012). By examining how people with conspiracist beliefs reconcile them with more conventional aspects of social reality, we can gain valuable insights into the construction and maintenance of political beliefs and intersubjective reality more generally (Hoffman 2016; Garrido 2017). There is more to learn about how institutions understand populist resistance to their agendas and how that affects public policy. Likewise, there is much to be gained by understanding how the conspiracy theorizing intersects with race and class, and how belief in conspiracy theories can be helpful or harmful to disadvantaged or oppressed communities (Simmons and Parsons 2005). While this essay has focused on the U.S. political sphere, comparative studies across national boundaries could illuminate the influences of specific political cultures and histories on the efficacy, extent, and content of thinking within the populist risk imaginary.

Future work would also be based on a more systematic dataset to examine the rhetoric and nature of the populist risk imaginary. Online forums like 4chan, $8 \mathrm{chan}$, and Reddit, or social media platforms like Twitter and YouTube could provide rich sets of 
textual and network data. Letters to the editor and comments on mainstream media websites would also be potentially useful sources of data. In-depth interviews with propagators and believers of conspiracy theories could qualitatively deepen our understanding of the meaning-making at work among social actors.

However future work proceeds, it is important that we look more closely at a phenomenon that so clearly influences political culture. 


\section{REFERENCES}

Aisch, Gregor, Jon Huang, and Cecilia Kang. 2016. "Dissecting the \#PizzaGate Conspiracy Theories." The New York Times.

Anderson, Ben. 2010. "Preemption, precaution, preparedness: Anticipatory action and future geographies." Progress in Human Geography. 34 (6):777-798.

Aradau, Claudia and Rens van Munster. 2012. "The Time/Space of Preparedness: Anticipating the "Next Terrorist Attack"." Space and Culture. 15 (2):98-109.

Bail, Christopher A. 2012. "The Fringe Effect: Civil Society Organizations and the Evolution of Media Discourse about Islam since the September 11th Attacks." American Sociological Review. 77 (6):855-879.

—. 2014. Terrified: How Anti-Muslim Fringe Organizationas Became Mainstream. Princeton and Oxford: Princeton University Press.

Barkun, Michael. 2006. A Culture of Conspiracy: Apocalyptic Visions in Contemporary America: University of California Press.

Beck, Ulrich. 1992. Risk society: Towards a new modernity: Sage Publications Limited. . 2009. World at Risk. Malden, MA: Polity Press.

Bierly III, Paul E. 1995. "Culture and High Reliability Organizations: The Case of the Nuclear Submarine." Journal of Management. 21 (4):639-656.

Bonikowski, Bart and Noam Gidron. 2016. "The Populist Style in American Politics:

Presidential Campaign Discourse, 1952-1996." Social Forces. 94 (4):1593-1621.

Brubaker, Rogers. 2017. "Why populism." Theory and Society. 46 (5):357-385.

Brussell, Mae. 2014. The Essential Mae Brussell: Investigations of Fascism in America. Edited by Alex Constantine: Feral House.

Burdick, Alan. 2018. "Looking for Life on a Flat Earth." The New Yorker.

Cable, Sherry, Thomas E Shriver, and Tamara L Mix. 2008. "Risk Society and Contested Illness: The Case of Nuclear Weapons Workers." American Sociological Review. 73 (3):380-401.

Cerulo, Karen. 2006. Never Saw it Coming: Cultural Challenges to Envisioning the Worst. Chicago, IL: University of Chicago Press.

Clarke, Lee. 1999. Mission Improbable: Using fantasy documents to tame disaster. Chicago: University of Chicago Press.

Clarke, Steve. 2002. "Conspiracy theories and conspiracy theorizing." Philosophy of the Social Sciences. 32 (2):131-150.

Collier, Stephen J. 2008. "Enacting catastrophe: preparedness, insurance, budgetary rationalization." Economy and Society. 37 (2):224-250.

Cosgrove, Jaclyn, Alejandra Reyes-Velarde, and Alene Tchekmedyian. 2018. "It's all going to burn:' Man accused of setting Holy fire was a well-known troublemaker, neighbors say." Los Angeles Times.

Daipha, Phaedra. 2015. Masters of Uncertainty: Weather Forecasters and the Quest for Ground Truth. Chicago, IL: Chicago University Press. 
Dalrymple II, Jim. 2018. "The Man Arrested For Allegedly Starting A Massive Wildfire Pushed Rightwing Conspiracy Theories." Buzfeed.

DiGrazia, Joseph. 2017. "The social determinants of conspiratorial ideation." Socius. 3:2378023116689791.

Dunlap, Riley E and Robert J Brulle, ed. 2015. Climate Change and Society. New York: Oxford University Press.

Fine, Gary Alan. 2007. Authors of the Storm: Meteorologists and the Culture of Prediction. Chicago: University of Chicago Press.

Fligstein, Neil, Jonah Stuart Brundage, and Michael Schultz. 2017. "Seeing Like the Fed: Culture, Cognition, and Framing in the Failure to Anticipate the Financial Crisis of 2008." American Sociological Review. 82 (5):879-909.

Fosher, Kerry. 2009. Under Construction: Making Homeland Security at the Local Level. Chicago: University of Chicago Press.

Garrido, Marco. 2017. "Why the poor support populism: the politics of sincerity in Metro Manila." American Journal of Sociology. 123 (3):647-685.

Gauchat, G. 2015. "The Political Context of Science in the United States: Public Acceptance of Evidence-Based Policy and Science Funding." Social Forces.

Gibson, David R. 2011. "Avoiding Catastrophe: The Interactional Production of Possibility during the Cuban Missile Crisis." American Journal of Sociology. 117 (2):361-419.

Giddens, Anthony. 1990. The Consequences of Modernity. Stanford, CA: Stanford University Press.

- 1991. Modernity and self-identity: Self and society in the late modern age. Cambridge: Polity Press.

Herrman, John. 2018. "The Making of a No. 1 YouTube Conspiracy Video After the Parkland Tragedy." The New York Times.

Hochschild, Arlie Russell. 2016. "Donald Trump loves conspiracy theories. So do his supporters." The Washington Post. PostEverything.

Hoffman, Steve G. 2016. "The Practical Use of Other Realities: Taking Berger and Luckmann into the Wild." Cultural Sociology. 10 (1):109-124.

Hofstadter, Richard. 1996. "The Paranoid Style in American Politics." Pp. 1-40 in The Paranoid Style in American Politics and Other EssaysCambridge, MA: Harvard University Press.

Husting, Ginna and Martin Orr. 2007. "Dangerous Machinery: "Conspiracy Theorist" as a Transpersonal Strategy of Exclusion." Symbolic Interaction. 30 (2):127-150.

Jansen, Robert S. 2011. "Populist mobilization: A new theoretical approach to populism." Sociological theory. 29 (2):75-96.

Jolley, Daniel, Karen M. Douglas, Ana C Leite, and Tanya Schrader. 2019. "Belief in conspiracy theories and intentions to engage in everyday crime." British Journal of Psychology. 
Jolley, Daniel and K. M. Douglas. 2014. "The social consequences of conspiracism: Exposure to conspiracy theories decreases intentions to engage in politics and to reduce one's carbon footprint." British Journal of Psychology. 105 (1):35-56.

Juergensmeyer, Mark. 2003. Terror in the Mind of God: The Global Rise of Religious Violence: University of California Press.

Keller, Larry. 2010. "Fear of FEMA." Intelligence Report.

Lakoff, Andrew. 2017. Unprepared: Global Health in a Time of Emergency. Oakland: University of California Press.

Marwick, Alice and Rebecca Lewis. 2017. "Media manipulation and disinformation online." Data \&3 Society Research Institute.

Marx, Karl. 2008. The Eighteenth Brumaire of Louis Bonaparte. New York: International Publishers Co., Inc.

Miller, Joanne M, Kyle L. Saunders, and Christina E Farhart. 2016. "Conspiracy endorsement as motivated reasoning: The moderating roles of political knowledge and trust." American Journal of Political Science. 60 (4):824-844.

Mische, Ann. 2014. "Measuring futures in action: projective grammars in the Rio +20 debates." Theory and Society. 43 (3-4):437-464.

Molotch, Harvey. 2012. Against Security: How We Go Wrong at Airports, Subways, and Other Sites of Ambiguous Danger. Princeton, NJ: Princeton University Press.

Mudde, Cas. 2004. "The Populist Zeitgeist." Government and Opposition. 39 (4):541563.

Muirhead, Russell and Nancy L. Rosenblum. 2019. A Lot of People Are Saying: The New Conspiracism and the Assault on Democracy: Princeton University Press.

Nefes, Türkay Salim. 2013. "Political Parties' Perceptions and Uses of Anti-Semitic Conspiracy Theories in Turkey." The Sociological Review. 61 (2):247-264.

Norton, Richard K. 2014. "Agenda 21 and Its Discontents: Is Sustainable Development a Global Imperative or Globalizing Conspiracy." The Urban Lawyer. 46 (2):325-360.

Oliver, J. Eric and Thomas Wood. 2014. "Medical conspiracy theories and health behaviors in the United States." JAMA Intern Med. 174 (5):817-818.

Perrin, Andrew J. and Stephen Vaisey. 2008. "Parallel public spheres: Distance and discourse in letters to the editor." American Journal of Sociology. 114 (3):781-810.

Power, Michael. 2005. "Organizational responses to risk: the rise of the chief risk officer." Pp. 132-148 in Organizational Encounters with Risk, edited by Bridget Hutter and Michael Power. New York: Cambridge University Press.

Lewis, Rebecca. 2018. "Alternative Influence: Broadcasting the Reactionary Right on YouTube." Data 83 Society Research Institute.

Reich, Jennifer A. 2016. Calling the shots: Why parents reject vaccines. New York: NYU Press.

Roberts, Karlene H. 1990. "Some Characteristics of One Type of High Reliability Organization." Organization Science. 1 (2):160-176. 
Simmons, William Paul and Sharon Parsons. 2005. "Beliefs in conspiracy theories among African Americans: A comparison of elites and masses." Social Science Quarterly. $86(3): 582-598$.

Stampnitzky, Lisa. 2013. Disciplining Terror: How Experts Invented "Terrorism". New York: Cambridge University Press.

Swami, Viren, Rebecca Coles, Stefan Stieger, Jakob Pietschnig, Adrian Furnham, Sherry Rehim, and Martin Voracek. 2011. "Conspiracist ideation in Britain and Austria: evidence of a monological belief system and associations between individual psychological differences and real-world and fictitious conspiracy theories." British Journal of Psychology. 102 (3):443-463.

Tavory, Iddo and Nina Eliasoph. 2013. "Coordinating Futures: Toward a Theory of Anticipation." American Journal of Sociology. 118 (4):908-942.

Trapenberg Frick, Karen, David Weinzimmer, and Paul Waddell. 2015. "The politics of sustainable development opposition: State legislative efforts to stop the United Nation's Agenda 21 in the United States." Urban Studies. 52 (2):209-232.

Twenge, Jean M., W. Keith Campbell, and Nathan T. Carter. 2014. "Declines in trust in others and confidence in institutions among American adults and late adolescents, 1972-2012." Psychol Sci. 25 (10):1914-1923.

Uscinski, Joseph E. and Joseph M. Parent. 2014. American Conspiracy Theories. New York: Oxford University Press.

van der Linden, Sander. 2015. "The conspiracy-effect: Exposure to conspiracy theories (about global warming) decreases pro-social behavior and science acceptance." Personality and Individual Differences. 87:171-173.

Vaughan, Diane. 1999. "The Dark Side of Organizations: Mistake, Misconduct, and Disaster." Annual Review of Sociology. 25:271-305.

Vogus, Timothy J., Naomi B. Rothman, Kathleen M. Sutcliffe, and Karl E. Weick. 2014. "The affective foundations of high-reliability organizing." J. Organiz. Behav. 35 (4):592-596.

Vosoughi, Soroush, Deb Roy, and Sinan Aral. 2018. "The spread of true and false news online." Science. 359 (6380):1146-1151.

Wagner-Pacifici, Robin and Iddo Tavory. 2017. "Politics as a vacation." American Journal of Cultural Sociology. 5 (3):307-321.

Warner, Benjamin R. and Ryan Neville-Shepard. 2014. "Echoes of a Conspiracy: Birthers, Truthers, and the Cultivation of Extremism." Communication Quarterly. $62(1): 1-17$.

Weick, Karl E. 1987. "Organizational Culture as a Source of High Reliability." California Management Review. 29 (2):112-127.

Williamson, Elizabeth. 2018. "Truth in a Post-Truth Era: Sandy Hook Families Sue Alex Jones, Conspiracy Theorist." The New York Times. 
Wynne, Brian. 1989. "Sheepfarming after Chernobyl: A case study in communicating scientific information." Environment: Science and Policy for Sustainable Development. 31 (2):10-39. 